\title{
Pengembangan Model Economic Production Quantity Mengakomodasi Continue dan Discrete Demand serta Kebijakan Rework Secara Simultan
}

\author{
Nurike Oktavia ${ }^{1}$, Henmaidi ${ }^{2}$, Prima Fithri ${ }^{3}$ \\ ${ }^{1}$ Politeknik ATI Padang, Indonesia \\ ${ }^{2,3}$ Universitas Andalas, Padang, Indonesia
}

\section{ARTICLE INFORMATION}

Received: June 07,2020

Revised: June 19,2020

Accepted: June 25,2020

\section{KEYWORD}

$E P Q$

Continue demand,

Discrete demand,

Rework

\section{CORRESPONDENCE}

Name: Nurike Oktavia

E-mail: oktavianurike@kemenperin.go.id

\section{A B $\mathbf{S}$ T $\mathbf{R}$ A $\mathbf{C}$ T}

\begin{abstract}
Inventory of finished goods needs to be planned and controlled regularly. Fulfilling customer demand whenever and wherever is the main purpose of the supply. This issue is related to production activities. Many companies use the Economic Production Quantity (EPQ) Model in determining the size of their lot productions. This model is able to show how to minimize total production costs by reducing inventory costs. Customer behavior at PT XYZ makes product delivery divided into 2 types. The first type, finished goods is sent continuously in small amounts called continue demand. The second type, products is sent between certain time intervals in large quantities called discrete demand. Basic EPQ Model's parameters do not accommodate a system like this. In addition, PT XYZ requires rework for products that do not pass the quality test. Therefore, this research was developed to formulate EPQ model that can accommodate two types of demand, continue and discrete, as well as the existence of rework policy. This study tries to provide another approach in solving the derivation problem using the "Arithmetic-Geometric Mean" method. The results of this study will display a mathematical formulation to find the optimal production cycle time for PT XYZ. Numerical examples are discussed to show practical models.
\end{abstract}

\section{PENDAHULUAN}

Persediaan adalah salah satu aspek terpenting bagi perusahaan. Menurut [1], persediaan adalah cadangan yang disiapkan oleh perusahaan dalam jumlah tertentu, baik dalam kegiatan produksi atau jaringan logistik. Persediaan disiapkan dalam bentuk bahan baku, komponen, work-in-process, atau produk jadi.

Dalam lingkungan bisnis yang kompetitif dan dinamis, strategi yang dapat meminimalkan biaya persediaan, meningkatkan aliran persediaan, dan mengelola persediaan diperlukan untuk memenuhi permintaan konsumen [2]. Strategi ini harus didukung oleh adanya perencanaan produksi yang optimal sehingga produk dapat diproduksi dalam kapasitas yang tepat dan dapat dikirim ke pelanggan pada waktu dan jumlah sesuai pesanan.

Produksi dapat didefinisikan sebagai transformasi bahan baku menjadi barang jadi [3]. Menurut [4], penentuan berapa banyak produk yang harus diproduksi dan kapan waktu yang tepat untuk melakukannya adalah hal yang penting.

Hal ini dikarenakan rencana dapat berubah secara tak terduga. Penyebabbnya dapat berbagai macam, seperti kegagalan mesin, ketidak hadiran karyawan, keterlambatan transportasi, fluktuasi permintaan, atau bahkan adanya kebijakan rework pada produk cacat.

Perencanaan produksi dilakukan salah satunya dengan menentukan ukuran lot produksi. Dengan ditentukan ukuran lot, perusahaan dapat menyesuaikan jumlah produk yang diproduksi dengan demand customer.

Jika jumlah produksi melebihi daya serap konsumen, produk akan menumpuk digudang dan meningkatkan biaya simpan yang harus ditanggung perusahaan. Tetapi jika jumlah produksi kurang dari kebutuhan konsumen, maka perusahaan akan mengalami stockout. Kedua 
kondisi ini harus diseimbangkan sehingga dapat diminimalisir.

Dalam hal ini, model persediaan banyak digunakan untuk menentukan ukuran lot produksi optimal dan yang paling umum adalah Economic Production Quantity /EPQ [5]. Model EPQ mengarahkan perusahaan untuk meminimalkan total biaya produksi dengan mengurangi biaya persediaan [6].

[1] menyatakan bahwa ada tiga parameter dalam model EPQ dasar, yaitu demand, biaya set up dan biaya simpan persediaan. Namun, [7] berpendapat bahwa seiring perkembangan zaman ketiga parameter ini tidak cukup menangani masalah, karena belum mengadopsi kondisi realistis yang dihadapi oleh perusahaan. Sehingga saat ini banyak peneliti mengembangkan model EPQ dasar untuk memberikan solusi yang lebih akurat untuk menjaga kepuasan pemangku kepentingan dan meminimalkan biaya persediaan [8].

PT. XYZ memiliki jenis demand yang harus dipenuhi setiap hari dalam jumlah kecil dan demand dalam jumlah besar yang dikirim dalam rentang waktu tertentu. Pengiriman dengan interval waktu tertentu dilakukan untuk menghemat biaya mencapai lokasi customer yang cukup jauh atau dalam hal penggunaan moda transportasi yang khusus. Permintaan seperti ini selanjutnya disebut dengan permintaan diskrit atau discrete demand. Sehingga, tipe permintaan yang dipenuhi setiap hari akan disebut sebagai demand kontinu atau continue demand.

Sistem persediaan dengan permintaan diskrit dianggap lebih alami dalam konsep persediaan dinamis. Permintaan dengan pengiriman produk secara terusmenerus dalam model EPQ klasik saat ini dianggap tidak lagi realistis dan tidak sesuai dalam sistem rantai pasok [9]. Model EPQ dengan men-sinkronisasi kedua tipe demand ini telah dikembangkan oleh [10].

Model EPQ tersebut menemukan waktu produksi optimal untuk sistem persediaan dengan adanya continue dan discrete demand. Akan tetapi, PT XYZ memiliki kebijakan untuk me-rework produk produk yang tidak sesuai dengan standar kualitasnya. Sehingga ada probailitas peningkatan jumlah produksi per siklus waktu produksi.

Oleh karena itu, penelitian ini akan mengembangkan model EPQ dengan mengakomodasi continue demand, discrete demand dan rework.

\section{METODOLOGI}

Dalam penelitian ini, EPQ yang dikembangkan bertujuan untuk menentukan waktu siklus produksi optimal $T$ dan jumlah pengiriman per tahun $n$. Dengan ditemukannya waktu siklus produksi optimal, maka ukuran lot produksi optimal $Q^{*}$ akan dapat dihitung.

Adapun batasan dalam formulasi model ini adalah :

- Kegiatan produksi untuk single item product atau tidak untuk produk dengan banyak tipe

- Breakdown mesin tidak terjadi selama kegiatan produksi berlangsung

- Deteriorasi mesin dan peralatan tidak terjadi selama kegiatan produksi

- Product cacat / imperfect product selalu bisa dirework

- Tidak ada safety stock

- Selama waktu produksi tidak ada kegiatan konsumsi produk. Demand pada saat produksi di siklus ke $y$ dipenuhi dari produksi siklus sebelumnya $y-1$.

- Jumlah produk cacat / imperfect product bernilai konstan selama produksi berjalan.

Ketika produksi reguler berlangsung selama $t_{l}$, akan timbul produk cacat $x$ sebagai efek samping dari kegiatan produksi yang ditampilkan dalam bentuk persentase. Seluruh imperfect product dikerjakan ulang setelah produksi reguler diselesaikan, yaitu selama $t_{2}$.

Produk didistribusikan / keluar dari perusahaan dengan dua tipe, (1) dikirim setiap hari untuk memenuhi continue demand dan (2) dikirim dalam interval waktu tertentu untuk memenuhi disceret demand. Inventory behaviour dari sistem yang akan dimodelkan digambarkan pada Gambar 1.

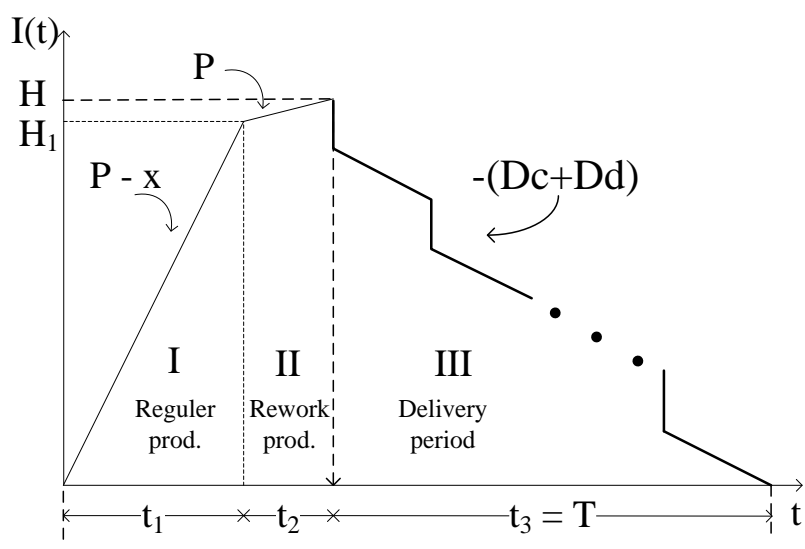

Gambar 1. Inventory Behaviour Model EPQ dengan Contiue Demand, Discrete Demand dan Rework 


\section{Notasi}

Decision variabels

$\mathrm{T}$ : Siklus produksi (waktu)

$\mathrm{n}$ : Frekuensi pengiriman demand discrete dalam satu siklus (bilangan integer)

\section{Notations}

Q : Ukuran lot produksi (unit)

$\mathrm{I}(\mathrm{t}) \quad$ : Jumlah persediaan pada waktu $t$ (unit)

$\mathrm{H}$ : Persediaan maksimal ketika produksi berakhir (unit)

$\mathrm{H}_{1}$ : Persediaan maksimal ketika rework berakhir (unit)

$\mathrm{t}_{1} \quad$ : lama waktu produksi dalam satu siklus (waktu)

$\mathrm{t}_{2}$ : lama waktu rework dalam satu siklus (waktu)

$\mathrm{t}_{3}$ : waktu yang diperlukan untuk mengirimkan produk pada satu siklus (waktu)

h : Biaya simpan (Rp/unit.waktu)

$\mathrm{h}_{1} \quad$ : biaya simpan produk yang ditanggung konsumen (Rp/unit.waktu)

$\mathrm{c}_{\mathrm{p}} \quad$ : biaya produksi (Rp/unit)

cs : biaya set up mesin (Rp)

$\mathrm{c}_{\mathrm{f}} \quad$ : biaya pengiriman tetap (Rp)

$\mathrm{c}_{\mathrm{d}} \quad$ : biaya pengiriman variabel (Rp)

x : Rasio produk cacat (unit/waktu)

$\mathrm{p} \quad$ : Kapasitas produksi (unit/waktu)

D : Demand total (unit)

$\mathrm{D}_{\mathrm{C}}$ : Demand continue (unit)

$\mathrm{D}_{\mathrm{D}}$ : Demand discrete (unit)

$\mathrm{x}_{\mathrm{D}}$ : Proporsi produk cacat untuk continue demand (\%)

$\mathrm{x}_{\mathrm{D}}$ : Proporsi produk cacat untuk discrete demand $(\%)$

$\mathrm{TC}(\mathrm{T}, \mathrm{n})$ : biaya total per siklus (Rp)

$\mathrm{E}[\mathrm{TCU}(\mathrm{T}, \mathrm{n})]$ : biaya rata-rata satu periode produksi (Rp)

\section{HASIL DAN PEMBAHASAN}

Frekuensi stock replenishment dalam 1 tahun $1 / T$ merupakan pembagian antara demand produk $D$ dengan ukuran lot size produksi $Q$,

$T=Q / D$

Sehingga

$t_{l}$, waktu produksi adalah:

$=\frac{Q}{P}=\frac{T D}{P}$

$t_{2}$ waktu rework:

$=\frac{\left(Q_{C} x_{C}+Q_{D} x_{D}\right)}{P}$

$=\frac{T\left(D_{C} x_{C}+D_{D} x_{D}\right)}{P}$ $\mathrm{t}_{3}$, waktu untuk mengirimkan produk pada satu siklus:

$t_{3}=\mathrm{T}$

Persediaan maksimal $H$ adalah:

$\mathrm{H}=\mathrm{Q}=\mathrm{TD}$

Sedangkan persediaan maksimal ketika terjadi imperfect product $H_{1}$ adalah :

$$
\begin{aligned}
\mathrm{H}_{1} & =(1-\mathrm{x}) \mathrm{Q} \\
& =(1-\mathrm{x}) \mathrm{TD}
\end{aligned}
$$

Persamaan (4) an (5) juga berlaku untuk jumlah persediaan maksimum continue demand dan discrete demand, yaitu

$\mathrm{H}_{\mathrm{C}}=\mathrm{Q}_{\mathrm{C}}=\mathrm{TD}_{\mathrm{C}}$

$\mathrm{H}_{\mathrm{C} 1}=(1-\mathrm{x}) \cdot \mathrm{Q}_{\mathrm{C}}=(1-\mathrm{x}) \cdot \mathrm{TD}_{\mathrm{C}}$

$\mathrm{H}_{\mathrm{D}}=\mathrm{Q}_{\mathrm{D}}=\mathrm{TD}_{\mathrm{D}}$

$\mathrm{H}_{\mathrm{D} 1}=(1-\mathrm{x}) \cdot \mathrm{Q}_{\mathrm{D}}=(1-\mathrm{x}) \cdot \mathrm{TD}_{\mathrm{D}}$

\section{Biaya Produksi}

Dalam satu siklus, biaya produksi yang dibutuhkan adalah biaya produksi regular $c_{p}$ dan biaya produksi rework $c_{R}$. Jika diasumsikan kedua biaya tersebut adalah sama

$c_{P}=c_{R}$

Maka, formulasi biaya total menjadi

$c_{p} Q+c_{p} Q_{C} x_{C}+c_{p} Q_{D} x_{D}$

Dengan mensubstitusi persamaan (1), maka

Total biaya produksi per siklus

$=c_{P}\left(T D+T D_{C} x_{C}+T D_{D} x_{D}\right)$

$=c_{p} T\left(D+D_{C} x_{C}+D_{D} x_{D}\right)$

Biaya Set Up Mesin

Biaya set up per siklus adalah

Total biaya set up $=c_{s}$

\section{Biaya Pengiriman}

Dalam studi kasus ini, biaya pengiriman dibagi menjadi biaya tetap $c_{f}$ dan biaya variabel $c_{d}$. Biaya tetap pengiriman per siklas dihitung berasarkan jumlah shipment pada siklus tersebut. Sedangkan biaya pengiriman variabel dihitung per unit produk untuk kedua tipe demand.

Total delivery cost $=n c_{F}+Q c_{d}$

\section{Biaya Simpan}

Formulasi biaya simpan dibagi menjadi dua bagian, yaitu biaya simpan persediaan demand continue dan demand discrete. 
Biaya Simpan untuk Continuous Demand

Berikut merupakan gambaran Inventory Behaviour untuk persediaan yang memenuhi demand continue.

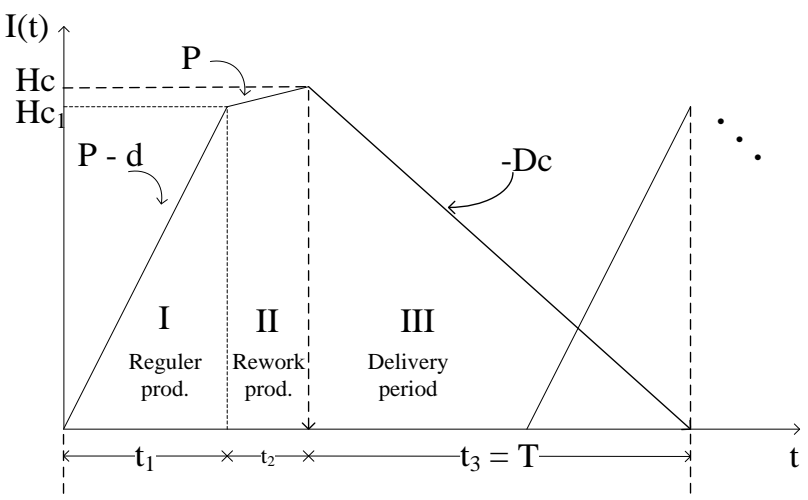

Gambar 2. Inventory Behaviour untuk Continuous

Demand

Persediaan rata-rata pada bagian I adalah :

$=\frac{1}{2} t_{1} H_{C 1}$

$=\frac{1}{2}\left(\frac{T D}{P}\right)\left(\left(1-x_{C}\right) T D_{C}\right)$

$=\frac{\left(1-x_{C}\right)}{2 P} T^{2} D D_{C}$

Kapasitas produksi regular $=$ kapasitas produksi pada saat melakukan rework $=$ P. Sehingga, persediaan ratarata pada bagian II adalah

$=\frac{\left(H_{C 1}+H_{C}\right)}{2} \cdot t_{2}$

$=\frac{\left[\left(1-x_{C}\right) T D_{C}\right]+\left(T D_{C}\right)}{2} \cdot \frac{T D x_{C}}{P}$

$=\frac{\left(2-x_{C}\right) T D_{C}}{2} \cdot \frac{T D x_{C}}{P}$

$=\frac{\left(2-x_{C}\right) T^{2} D D_{C} x_{C}}{2 P}$

Persediaan rata-rata pada bagian 3 yaitu

$=\frac{1}{2} t_{3} H_{C}$

$=\frac{1}{2} T\left(T D_{C}\right)$

$=\frac{1}{2} T^{2} D_{C}$

Maka, biaya simpan demand continue dalam satu siklus adalah

B. simpan demand continue per siklus $=$

$=h .\left[\frac{\left(1-x_{C}\right)}{2 P} T^{2} D D_{C}+\frac{\left(2-x_{C}\right) T^{2} D D_{C} x_{C}}{2 P}+\frac{1}{2} T^{2} D_{C}\right]$

\section{Biaya Simpan untuk Discrete Demand}

Gambar 3 memperlihatkan Inventory Behaviour untuk discrete demand.

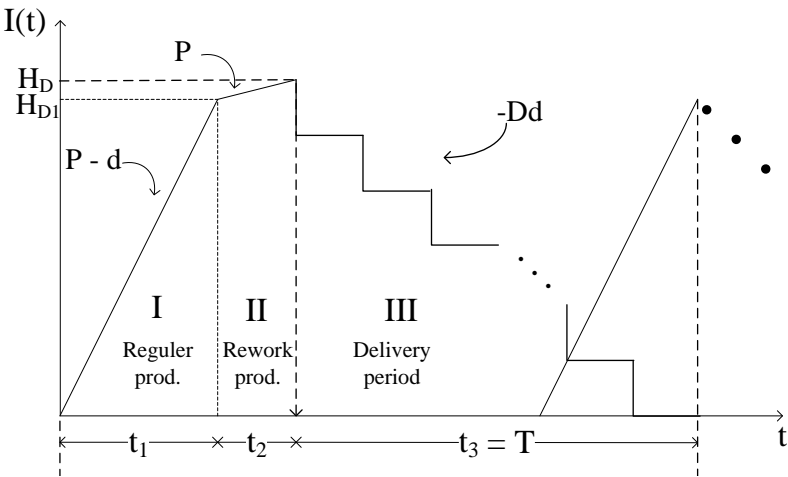

Gambar 3. Inventory Behaviour untuk Discrete Demand

Persediaan rata-rata pada bagian I adalah :

$=\frac{1}{2} t_{1} H_{D 1}$

$=\frac{1}{2}\left(\frac{T D}{P}\right)\left(\left(1-x_{D}\right) T D_{D}\right)$

$=\frac{\left(1-x_{D}\right)}{2 P} T^{2} D D_{D}$

Persediaan rata-rata pada saat melakukan rework/ bagian II adalah:

$$
\begin{aligned}
& =\frac{\left(H_{D 1}+H_{D}\right)}{2} \cdot t_{2} \\
& =\frac{\left[\left(1-x_{D}\right) T D_{D}\right]+\left(T D_{D}\right)}{2} \cdot \frac{T D x_{D}}{P} \\
& =\frac{\left(2-x_{D}\right) T D_{D}}{2} \cdot \frac{T D x_{D}}{P} \\
& =\frac{\left(2-x_{D}\right) T^{2} D D_{D} x_{D}}{2 P}
\end{aligned}
$$

Perhitungan persediaan rata-rata pada bagian 3 adalah sebagai berikut

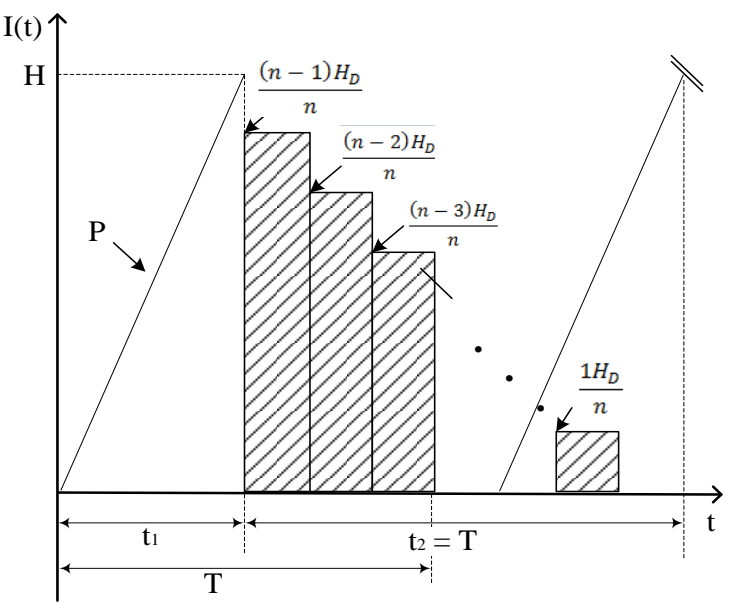

Gambar 4. Level Persediaan Demand Discrete Selama Masa Pengiriman Produk

Oktavia et al. 11 
Jadi, perhitungan persediaan rata-ratanya adalah:

$$
\begin{aligned}
& {\left[\frac{(n-1) H_{D}}{n} \frac{T}{n}\right]+\left[\frac{(n-2) H_{D}}{n} \frac{T}{n}\right]+} \\
= & {\left[\frac{(n-3) H_{D}}{n} \frac{T}{n}\right]+\ldots+\left[\frac{1 H_{D}}{n} \frac{T}{n}\right] } \\
= & \frac{H_{D} T}{n^{2}}\left[\frac{n(n-1)}{2}\right] \\
= & \frac{(n-1) H_{D} T}{2 n} \\
= & \frac{(n-1) T D_{D} T}{2 n} \\
= & \frac{(n-1) T^{2} D_{D}}{2 n}
\end{aligned}
$$

Sehingga, biaya simpan demand discrete dalam satu siklus adalah

B. simpan demand discrete per siklus $=$

$$
=h \cdot\left[\frac{\left(1-x_{D}\right)}{2 P} T^{2} D D_{D}+\frac{\left(2-x_{D}\right) T^{2} D D_{D} x_{D}}{2 P}+\frac{(n-1) T^{2} D_{D}}{2 n}\right]
$$

\section{Total Biaya Simpan}

Setelah diformulasikan biaya simpan untuk demand continue dan discrete pada persamaan (20) dan (24), maka biaya simpan persediaan untuk 1 siklus produksi

$$
=h\left[\begin{array}{l}
\frac{\left(1-x_{C}\right)}{2 P} T^{2} D D_{C}+ \\
\frac{\left(2-x_{C}\right) T^{2} D D_{C} x_{C}}{2 P}+ \\
\frac{1}{2} T^{2} D_{C}+\frac{\left(1-x_{D}\right)}{2 P} T^{2} D D_{D}+ \\
\frac{\left(2-x_{D}\right) T^{2} D D_{D} x_{D}}{2 P}+\frac{(n-1) T^{2} D_{D}}{2 n}
\end{array}\right]
$$

\section{Biaya Simpan yang Ditanggung Oleh Customer}

Ketika produk dari pengiriman discrete demand diterima oleh customer, terdapat biaya simpan yang harus dikeluarkan oleh customer tersebut. Hal ini dikarenakan ketika produk tiba sebanyak $H_{D} / n$, konsumsi produk tidak dilakukan sekaligus hingga stok habis namun secara bertahap.

Level persediaannya akan menjadi seperti berikut:

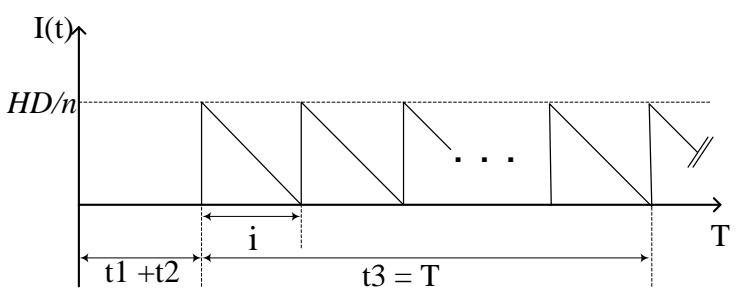

Gambar 5. Level Persediaan Discrete Demand yang Disimpan oleh Customer
Level persediaannya menjadi

$=\frac{1}{2} i \frac{H_{D}}{n}$

Dengan interval pengiriman $i$ adalah $T / n$, serta jumlah pengiriman per siklus aalah $n$, maka level persediaanya

$=\left(\frac{1}{2} \frac{T H_{D}}{n^{2}}\right) n$

Substitusikan dengan persamaan (9) sehingga

$=\frac{T^{2} D_{D}}{2 n}$

Maka,

Biaya simpan persediaan oleh customer

$=h\left[\frac{T^{2} D_{D}}{2 n}\right]$

\section{Fungsi Tujuan}

Total biaya per siklus $T C(T, n)$ terdiri dari biaya produksi, biaya set up mesin, biaya simpan produk, baik oleh produsen maupun konsumen, serta biaya tetap dan variabel pengiriman.

Maka, $T C(T, n)$ merupakan penjumlahan dari persamaan (12), (14), (15), (20), (24), dan (29)

$$
T C(T, n)=\left[\begin{array}{l}
c_{P} T\left(D+D_{C} x_{C}+D_{D} x_{D}\right)+c_{S}+ \\
n c_{F}+c_{d} T D+\frac{h\left(1-x_{C}\right)}{2 P} T^{2} D D_{C}+ \\
\frac{h\left(2-x_{C}\right)}{2 P} D D_{C} x_{C}+\frac{h}{2} T^{2} D_{C}+ \\
\frac{h\left(1-x_{D}\right)}{2 P} T^{2} D D_{D}+\frac{h\left(2-x_{D}\right)}{2 P} D D_{D} x_{D} \\
+\frac{h(n-1)}{2 n} T^{2} D_{D}+\frac{h_{1}}{2 n} T^{2} D_{D}
\end{array}\right]
$$$$
=\left[\begin{array}{l}
c_{P} T\left(D+D_{C} x_{C}+D_{D} x_{D}\right)+c_{S} \\
+n c_{F}+c_{d} T D-\frac{h D D_{C} T^{2}}{2 P}\left(x_{C}{ }^{2}-x_{C}-1\right)+ \\
\frac{h}{2} T^{2} D_{C}-\frac{h D D_{D} T^{2}}{2 P}\left(x_{D}{ }^{2}-x_{D}-1\right)+ \\
\frac{h}{2} T^{2} D_{D}+\frac{T^{2} D_{D}}{n}\left(h_{1}-h\right)
\end{array}\right]
$$

Fungsi tujuan yang ingin dicari adalah biaya rata-rata satu periodeE[TCU(T,n)], yang merupakan hasil pembagian dari total biaya per siklus dibagi dengan

12 Oktavia et al. 
panjang waktu siklus.Maka, biaya rata-rata satu periode produksi E[TCU(T,n)] dapat dirumuskan menjadi

$E[T C U(T, n)]=\frac{T C(T, n)}{T}$

$\left[\begin{array}{l}c_{P} T\left(D+D_{C} x_{C}+D_{D} x_{D}\right)+c_{S}+ \\ n c_{F}+c_{d} T D-\frac{h D D_{C} T^{2}}{2 P}\left(x_{C}{ }^{2}-x_{C}-1\right)+ \\ \frac{h}{2} T^{2} D_{C}-\frac{h D D_{D} T^{2}}{2 P}\left(x_{D}{ }^{2}-x_{D}-1\right)+ \\ \frac{h}{2} T^{2} D_{D}+\frac{T^{2} D_{D}}{n}\left(h_{1}-h\right) \\ T\end{array}\right]$

$=\left[\begin{array}{l}c_{P}\left(D+D_{C} x_{C}+D_{D} x_{D}\right)+\frac{c_{S}}{T}+ \\ \frac{n c_{F}}{T}+c_{d} D-\frac{h D D_{C} T}{2 P}\left(x_{C}{ }^{2}-x_{C}-1\right)+ \\ \frac{h}{2} T D_{C}-\frac{h D D_{D} T}{2 P}\left(x_{D}{ }^{2}-x_{D}-1\right)+ \\ \frac{h}{2} T D_{D}+\frac{T D_{D}}{n}\left(h_{1}-h\right)\end{array}\right]$

\section{Penentuan Solusi Optimal}

Penentuan solusi optimal untuk menentukan nilai optimal dari fungsi biaya dilakukan dengan metode pendekatan bertahap [11].

Variabel keutusan adalah $\mathrm{T}$ dan $\mathrm{n}$, maka fungsi objectif diubah dengan konstanta :

$T, T^{-1}, n T^{-1}$ dan $T n^{-1}$

menjadi

$E[T C U(T, n)]=Z_{0}+Z_{1}(T)+Z_{2}\left(\frac{1}{T}\right)+Z_{3}\left(\frac{n}{T}\right)+Z_{4}\left(\frac{T}{n}\right)$

Where $\mathrm{Z}_{0}, \mathrm{Z}_{1}, \mathrm{Z}_{2}, \mathrm{Z}_{3}$, dan $\mathrm{Z}_{4}$ adalah

$\mathrm{Z}(0)=c_{P}\left(D+D_{C} x_{C}+D_{D} x_{D}\right)+c_{d} D$

$Z_{1}(T)=\left[\begin{array}{l}\frac{h}{2} D_{C}-\frac{h D D_{C}}{2 P}\left(x_{C}{ }^{2}-x_{C}-1\right)+ \\ \frac{h}{2} D_{D}-\frac{h D D_{D}}{2 P}\left(x_{D}{ }^{2}-x_{D}-1\right)\end{array}\right]$

$\mathrm{Z}_{2}\left(\frac{1}{T}\right)=\mathrm{c}_{s}$

$$
\begin{aligned}
\mathrm{Z}_{3}\left(\frac{n}{T}\right) & =\mathrm{c}_{F} \\
\mathrm{Z}_{4}\left(\frac{T}{n}\right) & =\frac{D_{D}}{n}\left(h_{1}-h\right)
\end{aligned}
$$

$$
\begin{aligned}
& E[\operatorname{TCU}(T, n)]=Z_{0}+Z_{1}(T)+Z_{2}\left(\frac{1}{T}\right)+Z_{3}\left(\frac{n}{T}\right)+Z_{4}\left(\frac{T}{n}\right) \\
& =\left[\begin{array}{l}
\left.Z_{0}+\frac{1}{T}\left[\left(\sqrt{Z_{1}} T\right)^{2}+\left(\sqrt{Z_{2}}\right)^{2}-2\left(\sqrt{Z_{1}} T\right)+\left(\sqrt{Z_{2}}\right)\right]+\right] \\
\frac{T}{n}\left[\left(\sqrt{Z_{3}} \frac{n}{T}\right)^{2}+\left(\sqrt{Z_{4}}\right)^{2}-2\left(\sqrt{Z_{3}} \frac{n}{T}\right)+\left(\sqrt{Z_{4}}\right)\right]+ \\
+\frac{1}{T}\left[2\left(\sqrt{Z_{1}} T\right)+\left(\sqrt{Z_{2}}\right)\right]+\frac{T}{n}\left[2\left(\sqrt{Z_{3}} \frac{n}{T}\right)+\left(\sqrt{Z_{4}}\right)\right]
\end{array}\right] \\
& =\left[\begin{array}{l}
\left.Z_{0}+\frac{1}{T}\left(\sqrt{Z_{1}} T-\sqrt{Z_{2}}\right)^{2}+\frac{T}{n}\left(\sqrt{Z_{3}} \frac{n}{T}-\sqrt{Z_{4}}\right)^{2}+\right] \\
2 \sqrt{Z_{1} Z_{2}}+2 \sqrt{Z_{3} Z_{4}}
\end{array}\right]
\end{aligned}
$$

Dengan menggunakan prinsip pada metode ArithmeticGeometric Mean (AGM), jika bilangan yang berada dalam bentuk kuadrat pada persamaan (37) dama dengan nol, maka fungsi tujuan akan bernilai minimal.

Oleh karena itu, persamaan kuadrat pada persamaan (37) disamadengankan nol

$$
\begin{aligned}
\left(\sqrt{Z_{1}} T-\sqrt{Z_{2}}\right)^{2} & =0 \\
\sqrt{Z_{1}} T & =\sqrt{Z_{2}} \\
T & =\sqrt{\frac{Z_{2}}{Z_{1}}}
\end{aligned}
$$

Maka, $T^{*}$ menjadi

$$
\begin{aligned}
& T^{*}=\sqrt{\frac{c_{s}}{\left[\begin{array}{l}
\frac{h}{2} D_{C}-\frac{h D D_{C}}{2 P}\left(x_{C}{ }^{2}-x_{C}-1\right)+ \\
\frac{h}{2} D_{D}-\frac{h D D_{D}}{2 P}\left(x_{D}{ }^{2}-x_{D}-1\right)
\end{array}\right]}} \\
& =\sqrt{\frac{c_{s}}{\frac{h D}{2}-\frac{h D}{2 P}\left[D_{C}\left(x_{C}{ }^{2}-x_{C}-1\right)+D_{D}\left(x_{D}{ }^{2}-x_{D}-1\right)\right]}} \\
& =\sqrt{\frac{c_{s}}{\frac{h D}{2}\left[1-\frac{D_{C}\left(x_{C}{ }^{2}-x_{C}-1\right)+D_{D}\left(x_{D}{ }^{2}-x_{D}-1\right)}{P}\right]}}
\end{aligned}
$$


Selanjutnya persamaan $(a-b)^{2}$ kedua pada persamaan (37) disamadengan nol kan

$$
\begin{aligned}
\left(\sqrt{Z_{3}} \frac{n}{T}-\sqrt{Z_{4}}\right)^{2} & =0 \\
\sqrt{Z_{3}} \frac{n}{T} & =\sqrt{Z_{4}} \\
n & =\sqrt{\frac{Z_{4}}{Z_{3}} T}
\end{aligned}
$$

Dengan mensubstitusikan persamaan (35) dan (36) maka dapat diperoleh

$$
\begin{aligned}
n^{*} & =\sqrt{\frac{D_{D}\left(h_{1}-h\right)}{c_{F}}} T \\
& =\sqrt{\left.\frac{\frac{h D c_{f}}{2}\left[1-\frac{D_{C}\left(x_{C}{ }^{2}-x_{C}-1\right)+D_{D}\left(x_{D}{ }^{2}-x_{D}-1\right)}{P}\right]}{P}\right]}
\end{aligned}
$$

\section{Contoh Perhitungan}

Diketahui bahwa kapasitas produksi PT XYZ adalah 240 unit per menit. Total demand continue dan discrete per tahun adalah 60 juta unit. $60 \%$ untuk demand continue dan $40 \%$ untuk demand discrete. Diketahui bahwa mesin menghasilkan $7 \%$ imperfect item pada saat memproduksi continue demand dan 5\% untuk discrete demand. Diasumsikan bahwa seluruh imperfect item dapat di rework. Waktu kerja dalam satu ahri adalah 21 jam dan 360 hari per tahun.

Parameter lain adalah sebagai berikut :

$c_{s}: \operatorname{Rp} 30.000 .000 /$ set up

$c_{p}: \operatorname{Rp} 1.540 /$ unit

$c_{F}: \operatorname{Rp} 2.500 .000 /$ pengiriman

$c_{d}:$ Rp100/unit

$h$ : Rp440/unit.tahun

$h_{1}:$ Rp880/unit.tahun

Dengan menggunakan persamaan (37) dan (39) dapat ditentukan bahwa waktu siklus optimal $T^{*}=13,64$ hari dan jumlah pengiriman optimal $n^{*}=2,527$ kali. Karena $n$ merupakan bilangan integer maka dilakukan perhitungan persamaan (28). Jika $n^{*}=2$ maka biaya total per periode menjadi Rp106.044.391.263, dan jika $n *=3$ maka biaya total

\section{KESIMPULAN}

Formulasi model EPQ yang dirancang dapat membantu terselesaikannya permasalahan yang dihadapi oleh PT XYZ terkait adanya dua jenis demand, continue dan discrete serta kebijakan untuk me-rework produk cacat.
Akan tetapi, model ini masih banyak memiliki asumsi dan batasan. Kedepannya, akan lebih baik jika pengembangan model meminimalkan asumsi yang digunakan dalam formulasi sehingga model yang dirancang dapat mengakomodasi sistem nyata diperusahaan.

\section{DAFTAR PUSTAKA}

[1] Ballou, H. Ronald. (1992). Business Logistics Management.(Ed. 3). Prentice-Hall, Inc : New Jersey

[2] Beheshti, H. Hooshang. (2009). A Decision Support System for Improving Performance of Inventory Management in a Supply Chain Network. International Journal of Productivity and Performance Management. 59(15), 432-467

[3] Junger, Micheal dan Naddef Denis. (Ed.). (2001). Computational Combinatorial Optimization: Optimal or Provably NearOptimal Solution. Springer : Berlin

[4] Sipper, Daniel dan Bulfin, Robert. (1997). Production : Planning, Control, and Integration. McGraw-Hill: USA

[5] Eynan. (2003). The Benefit of Flexible Production Rates in the Economic Lot Scheduling Problem. IIE Transaction. 35 (7), 1057-1064

[6] Chiu, P.Y., Lin, K.C., Chang, H., Chiu, V. (2010). Mathematical Modelling for Determining Economic Batch Size and Optimal Number of Deliveries for EPQ Model with Quality Assurance.Mathematical and Computer Modelling of Dynamical System. 16 (4), 373-388

[7] Kostic, Konstantin. (2007). Inventory Control as a Discrete System Control for the Fixed-Order Quantity System.Applied Mathematical Modelling.33, 4201 - 4214

[8] Maity, A.K., Maity, K., Mondal, S., danMaiti, M. (2007). A Chebyshev Approximation For Solving The Optimal Production Inventory Problem of Deteriorating Multi-Item. Mathematical and Computer Modelling. 45, 149161

[9] Chiu, S.W., Gong, D.C., Chiu, C.L., Chung, C.L. (2011). Joint Determination of The Production Lot Size and Number of Shipment for EPQ Model with Rework. Mathematical and Computational Applications. 16 (2), 317 - 328

[10] Oktavia, N., Henmaidi, Jonrinaldi. (2016). Pengembangan Model Economic Production Quantity (EPQ) dengan Sinkronisasi Demand Kontinu dan Diskrit Secara Simultan. Jurnal Optimasi Sistem Industri. 15 (1), 78-86 
[11] Chen, Kuang-Ku dan Chiu, Singa Wang. (2011). Replenishment Lot Size and Number of Shipments for EPQ Model Derived Without Derivatives. Mathematical and Computational Applications. 16 (3), 753-760 